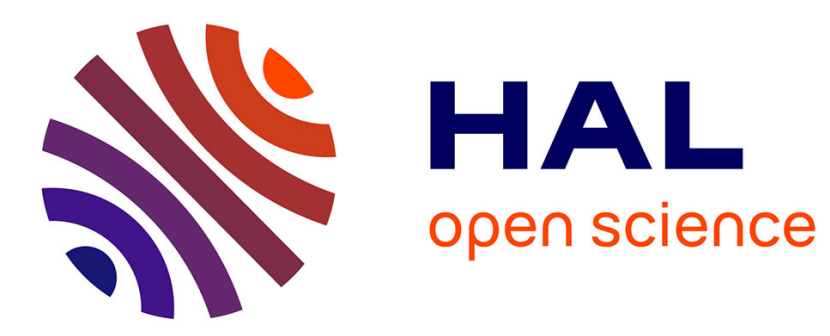

\title{
A new test method to simulate low-severity wear conditions experienced by rubber tire materials
}

M. Huang, M. Guibert, Jean Thevenet, C. Fayolle, T. Chaussée, L. Guy, L. Vanel, J.-L. Loubet, P. Sotta

\section{- To cite this version:}

M. Huang, M. Guibert, Jean Thevenet, C. Fayolle, T. Chaussée, et al.. A new test method to simulate low-severity wear conditions experienced by rubber tire materials. Wear, 2018, 410-411, pp.72-82. 10.1016/j.wear.2018.06.004 . hal-02389813

\section{HAL Id: hal-02389813 https://hal.science/hal-02389813}

Submitted on 18 Feb 2021

HAL is a multi-disciplinary open access archive for the deposit and dissemination of scientific research documents, whether they are published or not. The documents may come from teaching and research institutions in France or abroad, or from public or private research centers.
L'archive ouverte pluridisciplinaire HAL, est destinée au dépôt et à la diffusion de documents scientifiques de niveau recherche, publiés ou non, émanant des établissements d'enseignement et de recherche français ou étrangers, des laboratoires publics ou privés. 


\title{
Accepted Manuscript
}

\section{A new test method to simulate low-severity wear conditions experienced by rubber tire materials}

\author{
M. Huang ${ }^{1,2}$, M. Guibert ${ }^{2}$, J. Thévenet ${ }^{1,2}$, C. Fayolle $^{3}$, T. Chaussée ${ }^{3}$, L. \\ Guy $^{3}$, L. Vanel ${ }^{4}$, J-L. Loubet ${ }^{2}$, P. Sotta ${ }^{1 *}$ \\ ${ }^{1}$ Laboratoire des Polymères et Matériaux Avancés (LPMA), CNRS/Solvay UMR 5268, \\ 87 avenue des frères Perret, 69192 Saint Fons Cedex, France \\ ${ }^{2}$ Laboratoire de Tribologie et Dynamique des Systèmes (LTDS), CNRS/École Centrale \\ de Lyon UMR 5513, 36, avenue Guy de Collongue - 69134 Écully, France \\ ${ }^{3}$ Solvay Silica, 15 rue Pierre Pays, 69660 Collonges au Mont d'Or, France \\ ${ }^{4}$ Institut Lumière Matière (ILM), Univ Lyon, CNRS/Université Claude Bernard Lyon I \\ UMR5306, Villeurbanne, France \\ * corresponding author: paul.sotta-exterieur@solvay.com
}

\begin{abstract}
An innovative rotary tribometer was developed in order to reproduce the abrasive wear of reinforced rubber materials for tire. The device allows performing accelerated, quantitative friction and wear tests which mimic real usage conditions in terms of kinematics and dynamics of the contact, temperature and open cycle conditions, specifically in low severity conditions, which often represent a challenge to mimic and study. The specific point emphasized here is the strong impact of wear debris accumulated in the contact zone on the measured wear rate. To quantify this phenomenon, the amount of wear debris in the contact was varied by changing the frequency at which debris are eliminated. It was found that the presence of more debris in the contact zone generally decreases the wear rate. Two distinct types of wear debris were identified, which are likely to correspond to two distinct mechanisms of wear. Within a transitory period at the beginning of the tests, wear debris essentially consist in a sticky layer of soluble (thus decrosslinked elastomer material). Further on, a steady regime (representative of wear in real low severity conditions) occurs, with a well established ridge pattern, in which the predominant wear mechanism consists in tearing away material fragments of micrometric sizes. The proposed test method allows discriminating quantitatively these mechanisms.
\end{abstract}




\section{Accepted Manuscript}

Keywords: Tribometer, wear, abrasion, rubber, reinforced elastomers

\section{Introduction}

Considering the lifetime of tires, the wear resistance is of undisputed importance for tire tread materials [1-4]. However, evaluating the wear property of rubbery materials in a realistic way is still a challenging task. On one side, in-field wear tests are costly and time consuming. On the other hand, in-field wear processes are complex. Different road and/or climate conditions, and even the driving habit, can have large impact on the testing results. Therefore, modelling and predicting wear resistance with laboratory tests remains a major issue. Though laboratory testers have been developed, the tire industry is still in need for better laboratory solutions to characterize the wear performance of rubber materials and fasten material selection.

The general concept of a wear test is to apply normal load together with slip between the material of interest and a abrading surface while interfacial friction induces wear of both sides. Accordingly, the wear rate of the material can be described by the weight or volume loss per unit sliding length or per unit frictional energy. For example, abradability can be defined as abraded volume per unit energy dissipation [5]. A proper laboratory tribometer should be able to provide well controlled testing conditions as close to the real in-field situation as possible. For example, for a passenger car tire running at a constant $90 \mathrm{~km} /$ hour speed, the tread material faces a periodic pressure of about $0.3 \mathrm{MPa}(0.7 \mathrm{MPa}$ for a truck tire) at a frequency of about $10 \mathrm{~Hz}$ [6]. Meanwhile, the tire slips against the road on its trailing edge when the contact is released, even without a relative speed between the road (e.g. even without acceleration, braking or steering). This is due to lateral compressive strain developing in the contact surface (Figure 1). Each contact contributes a slip length in a range of a fraction of a millimeter at a sliding velocity of a few centimeters per second [6]. Also, relatively high shear rates -of order a hundred $\mathrm{s}^{-1}$ - are applied as a point of the material enters or exit the contact. Altogether, the wear is roughly of the order $2.5 \times 10^{-6} \mathrm{~m}$ of abraded height per slip meter for a truck tire tread in soft conditions. Thus, in order to model the real situation, a laboratory wear tester for rubber materials should be controlled intermittently (periodically switching between slide and non-slide mode, or load and unload mode). This is quite important and completely opposite results may be obtained if this point is ignored, as 


\section{Accepted Manuscript}

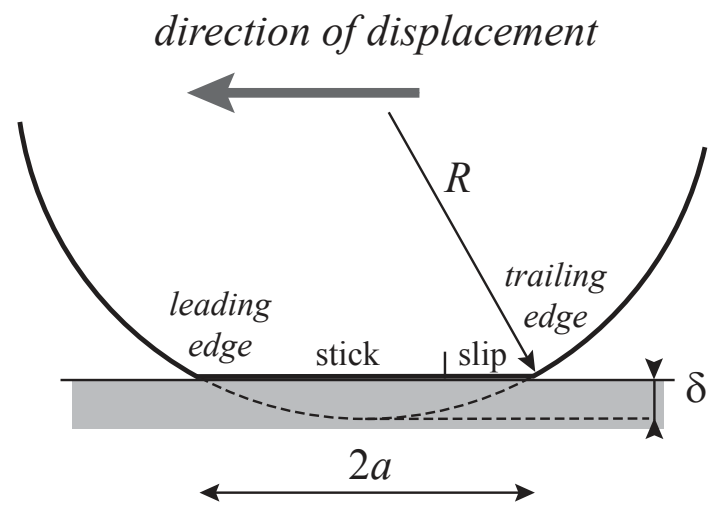

Figure 1: Schematics of the contact zone of a tire tread groove. Slip occurs at the trailing edge of the contact zone, where the tangential over normal stress ratio becomes larger than the friction coefficient $\mu$.

resilience, hysteresis, relaxation and fatigue behavior of rubber considerably impact the wear $[1,2]$. Therefore, tests running only in a continuous way are not suitable to characterize tire tread materials.

Typically, intermittent tests can be achieved in two ways: one by rolling wheel shaped samples; another one by blade abrasion (Figure 2). Although they both can enable a intermittent wear under a certain frequency by tuning the speed of the motion part(s) (e.g. the Pico and Blade abraders [23, 27, 28]) or the sliding angle (e.g. the LAT 100 and Akron abraders [11, 12]), the actual sliding time/distance during a full period cannot be well controlled. Moreover, the normal force has to be fixed during the test by a dead load in most of the reported machines. Therefore, it is difficult to apply a dynamically controlled force profile.

Numerous studies have been performed to elucidate the mechanisms of abrasive wear of rubber-like materials [7-11, 13-24]. Blade abrasion has often been used. While it has proved to be very useful to elucidate wear pattern formation mechanisms [17-19], it is not directly representative of usage conditions. A sliding indenter rubbing on the rubber surface has also been used [6]. Contact sliding is a necessary condition to observe wear, i.e. abrasion weight loss. Indeed, it has been shown that wear is univoquely associated to slip and does not occur in indentation experiments in the absence of slip $[4,25,26]$.

Generally speaking, there are two types of wear: the first one, known as 


\section{Accepted Manuscript}

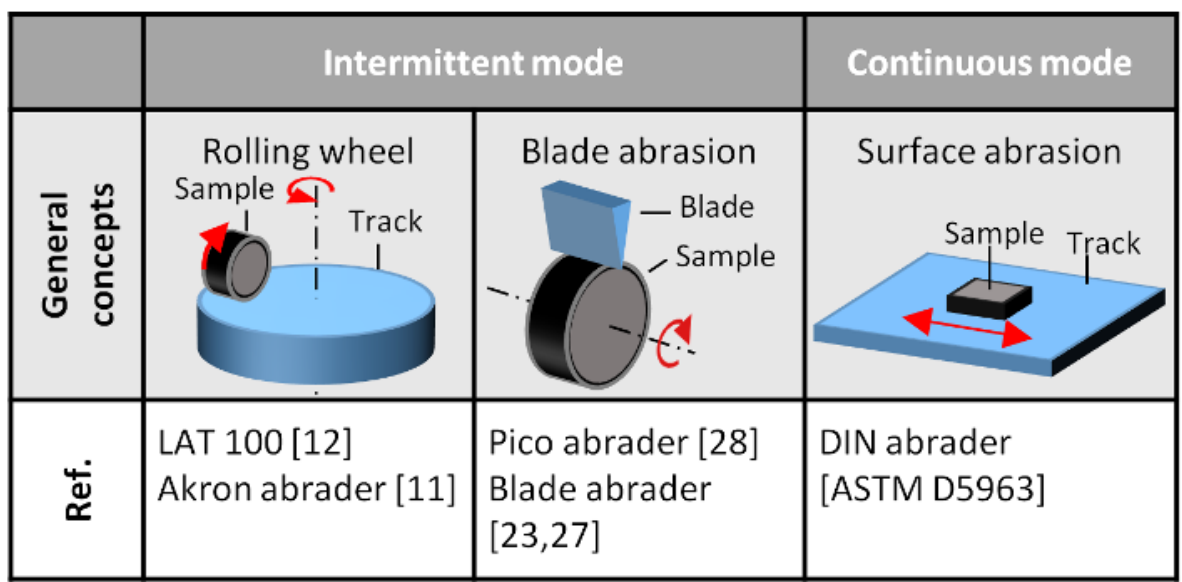

Figure 2: Laboratory wear testers classified according to their contact modes. A comprehensive introduction is made by ISO 23794. Note that the pictures shown in this table only indicate general concepts rather than a layout of any real machine.

intrinsic wear, generates very small rubber particles of a few micrometers. This dimension was found to be independent of the applied normal force [27]. It essentially depends on the intrinsic characteristic size of the asperities of the abrading surface $[17,29,30]$. As wear goes on, periodical patterns perpendicular to the sliding direction may be generated. This type of wear is called pattern abrasion and normally causes an increase of the wear. Pattern abrasion is related to tear mechanism and the wear rate can be predicted by the tearing energy $[31,32]$. Besides those two mechanisms, smearing of rubber was also observed in many cases, especially for NR and SBR compounds. Smearning generates a soft and sticky rubber layer on the contact surfaces, which is believed to be caused by thermal degradation and oxidation of the rubber material and strongly impacts the measured wear rate [2]. However, the mechanism behind is not fully clear yet.

The objective of this paper is to present new results of abrasion tests performed with a new experimental device (tribometer), which has been developed in order to model the wear of a tire tread in low severity conditions, under controlled environmental parameters. This device can be used to generate and characterize wear patterns in controlled, representative conditions, such as sample geometry, sliding speed, normal force, friction coefficient (by tuning the roughness of the disk) and temperature, with high repeatability. 


\section{Accepted Manuscript}

Preliminary results obtained on some representative materials are shown. The main result that is emphazised here is the strong impact of the accumulation of wear debris in the contact zone. This is evidenced and quantified by measuring the effect of the cleaning frequency on the overall wear rate in a given sample under a given set of parameters.

Third body effects, either due to debris generated in-situ or due to exogenic abrasive particles, are widely documented in general wear studies of solid polymers [33]. On the other hand, rubber wear studies have mainly been focussed on two-body abrasion and on viscoelastic and fracture mechanisms associated to local roughness of the abrading surface [29, 30], including the most recent experimental and modeling studies [34]. There are only a limited number of published studies which explicitly address the effects of a third body, and these are mainly dealing with exogenic abrading agents such as particles immersed in an abrasive liquid [35, 36].

The paper is organized as follows. The studied material formulations are described in section 2.1, their mechanical properties are described in section 2.2. The tribometer is described in section 2.3 and test procedures and analyzes in section 2.4. Results are presented in section 3.

\section{Materials and methods}

\subsection{Materials}

The studied materials are Natural Rubber (NR CV60) matrices reinforced either with carbon black fillers (N121 from Cabot, sample C1) or highly dispersible precipitated silica (Zeosil ${ }^{\circledR}$ 1165MP by Solvay, sample S2), as reported in Table 1. Samples were provided by Solvay Silica (Collongesau-Mont-d'Or, France). N121 has a specific surface of about $100 \mathrm{~m}^{2} / \mathrm{g}$ while Z1165 has about $160 \mathrm{~m}^{2} / \mathrm{g}$. The silica was treated with triethoxysilylpropyltetrasulfur (TESPT), which covalently links the silica surface to the NR matrix. Samples were processed in a 1.5 liter intermeshing internal mixer (Brabender $380 \mathrm{~cm}^{3}$ ) and sulfur vulcanized at a temperature of $145^{\circ} \mathrm{C}$ and a pressure of $30 \mathrm{MPa}$ for $15 \mathrm{~min}$ resulting $2 \mathrm{~mm}$ thick sample sheets. They were cut into $10 \times 2 \mathrm{~mm}$ or $18 \times 2 \mathrm{~mm}$ disks which were then glued to the sample holder using Loctite 480 glue. Sample surfaces were cleaned by acetone before doing the tests. 


\section{Accepted Manuscript}

\begin{tabular}{ccc}
\hline Component & C1 & S2 \\
\hline NR CV60 & 100 & 100 \\
N121 & 50 & \\
Zeosil $^{\circledR} 1165 \mathrm{MP}$ & & 55 \\
TESPT & & 4.4 \\
stearic acid $^{2}$ & 3 & 3 \\
ZnO & 3 & 3 \\
6PPD & 1.5 & 1.5 \\
Sulfur (rh80) & 1.5 & 1.5 \\
CBS (rh80) & 0.8 & 1.9 \\
TBzDT (rh70) & 0.2 & 0.2 \\
\hline
\end{tabular}

Table 1: Formulations of studied compounds. Units are in grams. 6PPD: N(1,3-dimethylbutyl)-N'-phenyl-P-phenylenediamine. CBS: N-cyclohexyl-2benzothiazyl. TBzDT: Tetrabenzylthiuramdisulfide.

\subsection{Mechanical characterization}

Wear resistance is closely related to the mechanical strength (e.g. tensile and tear), hardness and resilience of the materials. Mechanical properties of the materials have been characterized.The storage $(G)$ and loss $\left(G^{\prime \prime}\right)$ shear moduli were characterized at $40{ }^{\circ} \mathrm{C}$ in oscillatory shear at a frequency $10 \mathrm{~Hz}$ with a Metravib Dynamic Mechanical Analyzer. The variation of $G^{\prime}$ and $G^{\prime \prime}$ as a function of the strain amplitude $\gamma$ are shown in Figure 3. $G^{\prime}$ curves can be fitted with a heuristic function of the form [37]:

$$
G^{\prime}=G_{\infty}+\frac{\Delta G}{\left(1+\gamma / \gamma_{c}\right)^{\kappa}}
$$

Fits of the $G^{\prime}$ vs. strain amplitude curves are reported in Fig. 3. The obtained fitting coefficients for the three samples are summarized in Table 2. As commonly observed in such samples, the moduli at small amplitude and the Payne effect amplitudes $\Delta G$ are much larger in the carbon blackreinforced sample than in the silica reinforced one [38], while both samples have comparable values of the modulus $G^{\prime}$ at $50 \%$ amplitude.

Traction curves measured at $T=20^{\circ} \mathrm{C}$ and at $T=60^{\circ} \mathrm{C}$ are shown in Figure 4 for both samples. These curves have been obtained as the average over five different tests. The less pronounced non-linearity at small strain measured in Payne effect curves at $T=40^{\circ} \mathrm{C}$ for the silica-filled sample (see 


\section{Accepted Manuscript}

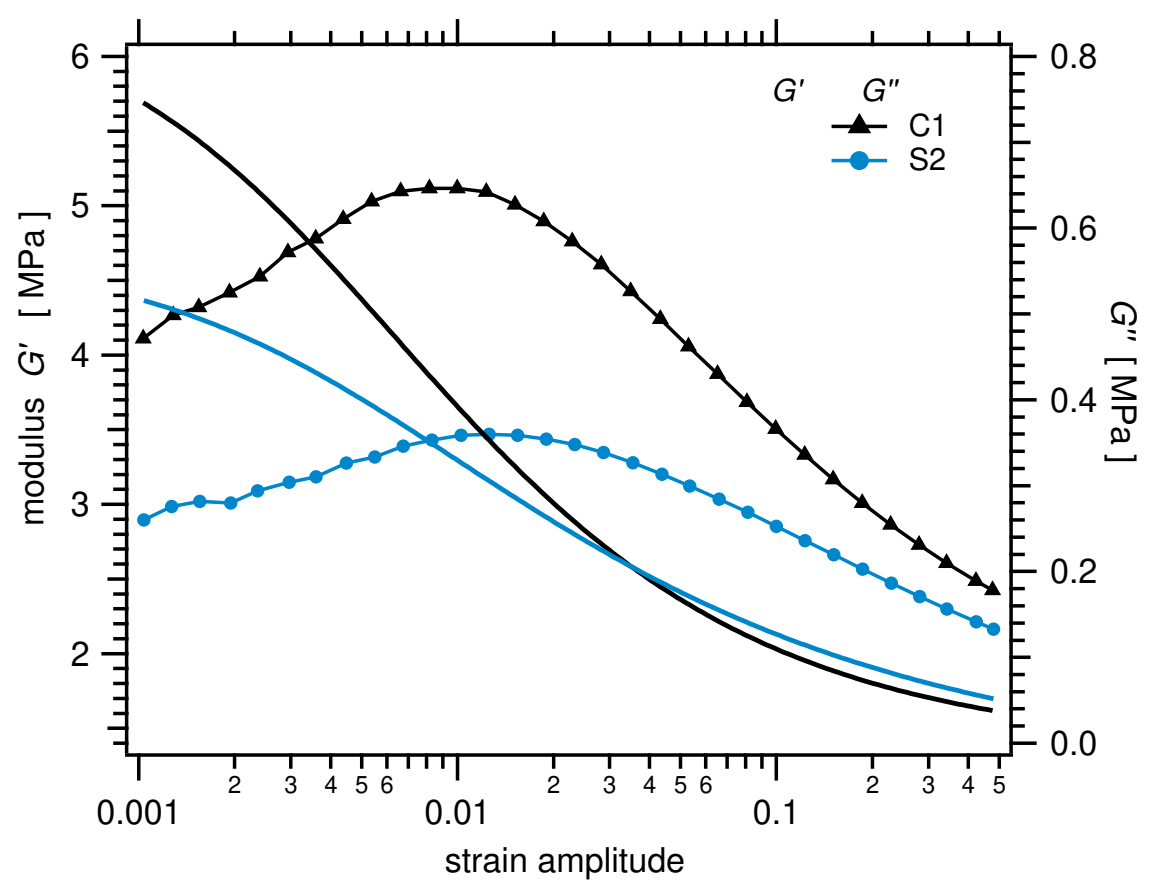

Figure 3: Storage $\left(G^{\prime}\right.$, empty symbols, axis on left) and loss $\left(G^{\prime \prime}\right.$, full symbols, axis on right) shear moduli at $10 \mathrm{~Hz}$ as a function of the strain amplitude (Payne effect) at $T=40^{\circ}$ for the studied materials C1 (filled with carbon black N121, triangles) and S2 (filled with silica, circles). Curves through symbols for $G^{\prime}$ are fits with the heuristic function Eq.3 . 


\section{Accepted Manuscript}

\begin{tabular}{ccc}
\hline Component & C1 & S2 \\
\hline$\Delta G$ & 5.02 & 3.48 \\
$\gamma_{c}$ & 0.381 & 0.403 \\
$G_{\infty}$ & 1.35 & 1.20 \\
$\kappa$ & 0.603 & 0.405 \\
\hline
\end{tabular}

Table 2: Values of the parameters obtained by fitting the $G^{\prime}$ curves in Figure 3 with the heuristic function in Eq. 1. Units for $\Delta G$ and $G_{\infty}$ are in $\mathrm{MPa}, \gamma_{c}$ values are in $\%$.

Figure 3) is hardly measurable in these curves. Only at $20^{\circ} \mathrm{C}$ does the curve for silica fillers show a more pronounced non linearity at small strain, as shown in the inset. Silica fillers result in a slightly lower modulus at high elongation, together with a slightly higher elongation at break.

\subsection{Experimental setup: Tribometer}

As mentioned in introduction, wear is due to slipping in the contact. The general concept of the new rotary tribometer is thus to produce intermittent slipping at the rubber surface, at controlled contact frequency, pressure and accumulated sliding length comparable to real tires. The device must work in open cycle mode, i.e. abrasion wastes must be eliminated between each passage. The new experimental device that we have developed is a rotary tribometer working in controlled environment, with an in situ optical observation system. Intermittent contacts with fully independent control of contact pressure, contact time, contact frequency and sliding velocity are applied. The displacement rates at both onset and release of contact can be controlled independently thanks to fast closed loop control of the normal force. The frequency of elimination of wear debris from the contact zone is also a key parameter, as will be discussed later.

The general architecture of the rotary tribometer is schematized in Figure 6. An horizontal abrading disk (label i in Figure 6) rotates around the vertical axis $(A)$ at the angular velocity $\omega($ in $\mathrm{rad} / \mathrm{s})$. It provides the sliding motion at a sliding velocity $v_{s}=R \omega$ where $R$ is the track radius, i.e. the distance between the sample and the axis $(A)$. In all tests shown here, $R$ was kept fixed to $10.25 \mathrm{~cm}$. The sliding direction is along $x$ in Figure 6 . The abrading disk (MICROPLAN FRANCE, label $\mathrm{i}$ in Fig. 6) is made of granite (granit bleu de Guéret), which maintains its surface roughness constant over test duration. The topography of the granite surface (granite 1200) was characterized with 


\section{Accepted Manuscript}

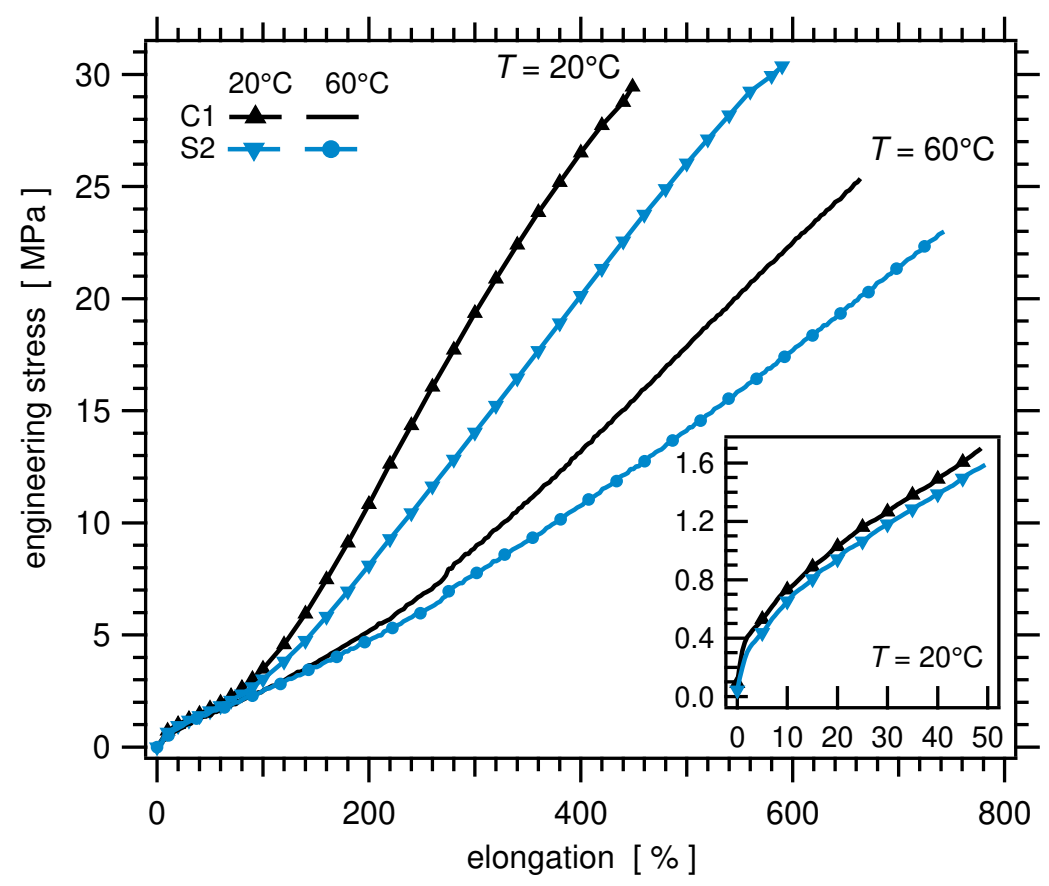

Figure 4: Tensile engineering stress as a function of elongation strain measured at $T=$ $20^{\circ} \mathrm{C}$ and $60^{\circ} \mathrm{C}$ for both samples $\mathrm{C} 1$ (filled with carbon black N121) and S2 (filled with silica). The inset is a zoom of the curves at $20^{\circ} \mathrm{C}$ to show the non-linearity at small strain. 


\section{Accepted Manuscript}

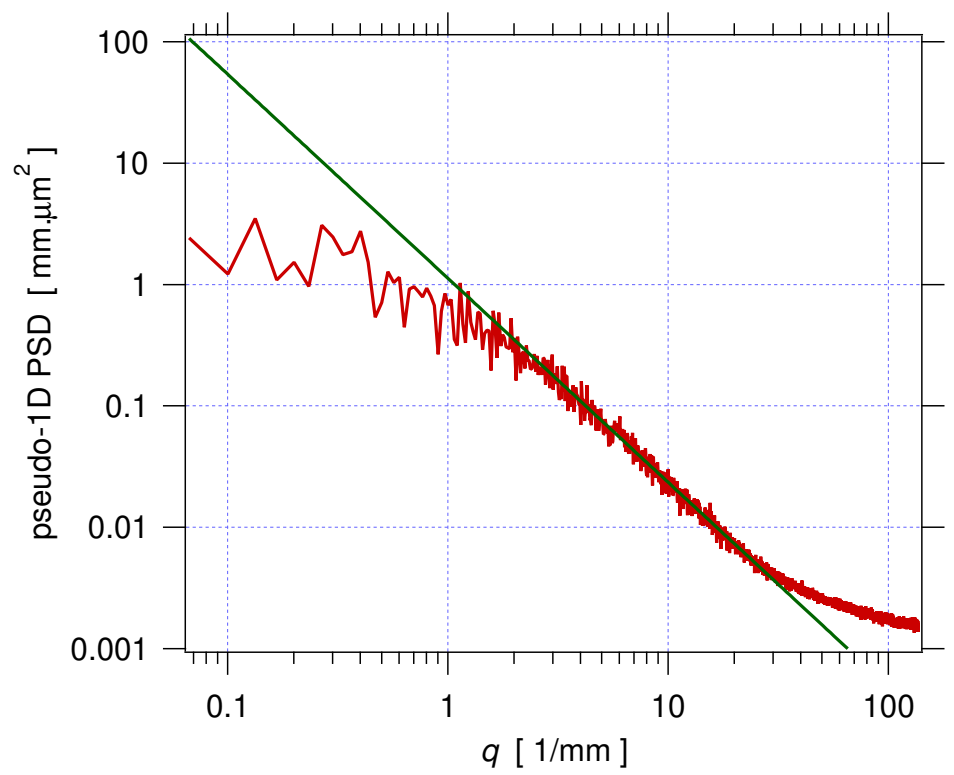

Figure 5: The average 1D PSD of the granite surface.

a Bruker 3400E optical interferometer using a $\times 5$ objective on the optical column and $\times 5$ at the camera. In this way, lateral resolution of order 2 $\mu \mathrm{m}$ and vertical resolution better than $0.1 \mathrm{~nm}$ are obtained. A $25 \times 1 \mathrm{~mm}^{2}$ image was obtained through numerical reconstruction from $301.3 \times 1 \mathrm{~mm}^{2}$ images. No difference was measured within and outside the wear track after more than 100 tests were performed. Figure 5 shows the averaged 1D power spectrum density of the surface. In the relevant $q$ range, the 1D PSD shows an exponent of order -1.68 , which is in full agreement with reported values for polished granite [39]. The surface is characterized by roughness indicators $\left\langle R_{a}\right\rangle=0.35 \pm 0.06 \mu \mathrm{m}$ and $\left\langle R_{t}\right\rangle=3.19 \pm 0.78 \mu \mathrm{m}$ for the fresh surface, while $\left\langle R_{a}\right\rangle=0.38 \pm 0.08 \mu \mathrm{m}$ and $\left\langle R_{t}\right\rangle=3.64 \pm 1.03 \mu \mathrm{m}$ for the cleaned worn surface, as measured by high resolution profilometry. These figures show that the surface roughness is indeed preserved during wear tests, which is not the case when e.g. polished stainless steel is used.

A fast piezoelectric dynamic actuator acting along vertical direction $z$ (label b) is used to control the duration and frequency of contacts and the normal force between the sample and the disk. It can provide either constant or intermittent loading. In this way, the contact and/or release times and 


\section{Accepted Manuscript}

the sliding velocity are controlled independently. The whole device is fully controlled by a dedicated home-made LabVIEW software. The piezoelectric actuator (P-602.8SL from PI, label b in Fig. 6) has a displacement range $\pm 0.5 \mathrm{~mm}$. It is driven by a fast force-controlled loop to ensure a stable normal force with a tolerance smaller than around five percent of the set value. The piezo-actuator is fixed on a 2D $y-z$ movable frame (label a). Therefore, the wear track can potentially be changed to provide access to fresh surface of the disk during the test.

A 3D load cell (KISTLER) (Figure 6 label e) measures the tangential (friction) force (along $x$ axis) and the normal force (along $z$ axis).

The aluminum sample holder (label c) is shaped as a cylinder of radius $100 \mathrm{~mm}$ with horizontal axis carefully set parallel to the abrading disk surface and perpendicular to the sliding direction (i.e. along $y$ ), as schematized in Figure 6). As mentioned in Section 2.1, samples are $2 \mathrm{~mm}$ thick disks of 10 or $18 \mathrm{~mm}$ diameter glued on the sample holder. A thermocouple thermal sensor (label f) is placed within the sample holder right to the rear of the sample and gives feedback to the heating unit. An optical camera (CMOS camera from R\&D VISION) (label g) coupled to a LED light source (R\&D VISION) (label h) records the whole wear process. In particular, the deformation of the sample during a contact can potentially be recorded in real time. Such data are not shown here.

\subsection{General procedure of wear tests}

The general test procedure is as follows: Step 1. The sample is glued on the sample holder, weighted and loaded in the tribometer. Sample orientation is carefully adjusted using optical camera; Step 2. Wait for temperature equilibration; Step 3. Wear test period of a given number of contacts; Step 4. Sample together with sample holder is unloaded and weighed. Step 5. The wear track is cleaned. The sample surface is cleaned and the sample together with the sample holder is weighed again. Step 6. Sample is loaded back in the tribometer and test is iterated from step 2.

For all results shown here, the sliding speed was fixed to $5 \mathrm{~cm} / \mathrm{s}$ during step 3. The actuator generates square pulses to provide cyclically intermittent slip with different normal forces varying from $10 \mathrm{~N}$ to $30 \mathrm{~N}$. The contact time is $1 \mathrm{~s}$ followed by a non-contact (relaxation) duration of $0.1 \mathrm{~s}$. Therefore, the full motion cycle (denoted as a 'wear-loop' in what follows) lasts $1.1 \mathrm{~s}$. After a wear test period, the disk surface will be contaminated by the wear debris which affects the wear rate. Therefore, after a given number of 


\section{Accepted Manuscript}

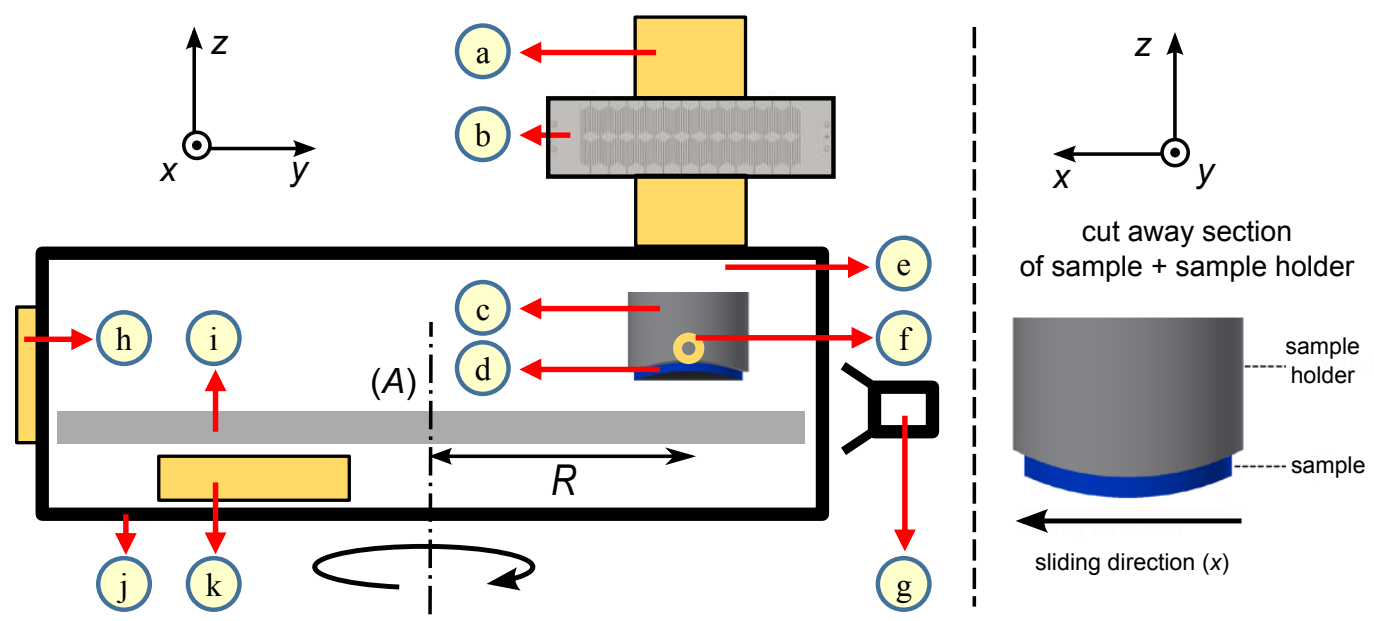

Figure 6: Schematics of the general architecture of the rotary tribometer. a: 2D movable frame ( $x$ and $z$ axis); b: piezo-electric actuator; c: sample holder; d: sample; e: 3D load cell; f: thermocouple; g: optical camera; h: LED lightning; i: rotating abrading disk; $\mathrm{j}$ : temperature and atmosphere controlled chamber; k: heating unit. Note that the abrading disk diameter and sample size are not drawn to scale.

wear-loops (e.g. every 500 wear-loops), the sample together with the sample holder is unmounted and the debris left on the track are removed physically by an eraser (STAEDTLER Mars plastic) and then chemically with acetone (Step 5). Debris are eliminated from the surface in exactly the same way as graphite particles are rubbed out from paper. Debris are stuck onto the very soft, sticky rubber material of the eraser and then eliminated together with the large eraser particles. The surface is then washed with acetone and blown with dry gas. At the same time, the sample surface is cleaned up with acetone and its weight loss is measured before and after cleaning. Such a testing period (from Step 2 to Step 6) is called a 'wear-stage'.

Wear is quantified by the weight loss of the sample during the wear test. Since elastomer materials are quite sensitive to the environment (hygrometry, temperature, ...), an identical unworn reference sample was always placed within the tribometer enclosure and its weight measured in parallel to that of the worn sample at each wear stage. This procedure allows to get rid of any change related to the environment (mostly potential moisture sorption).

At each wear-stage (number $n$ ), the weight of the wear debris left on the sample surface $\left(\Delta m_{\text {surface }}(n)\right)$ or on the abrading disk $\left(\Delta m_{\text {track }}(n)\right)$ during 


\section{Accepted Manuscript}

the current stage and the overall weight loss $\left(\Delta m_{\text {total }}(n)\right)$ are worked out as:

$$
\begin{gathered}
\Delta m_{\text {surface }}(n)=m_{b}(n)-m_{a}(n) \\
\Delta m_{\text {track }}(n)=m_{a}(n-1)-m_{b}(n) \\
\Delta m_{\text {total }}(n)=\Delta m_{\text {track }}(n)+\Delta m_{\text {surface }}(n)=m_{a}(n-1)-m_{a}(n)
\end{gathered}
$$

where $m_{a}(n)$ and $m_{b}(n)$ are the weights measured respectively after and before cleaning the sample for the current stage $n . m_{a}(n-1)$ is measured in the previous wear stage (right before starting stage $n$ ). All measurements were calibrated by measuring the weight change of the reference sample, which generally did not change by more than $0.02 \mathrm{mg}$, which is of the order of the resolution of the balance, while the weight loss per wear stage, i.e. per cycle of 500 wear-loops, is about $1 \mathrm{mg}$. The total accumulated weight loss after $N$ wear stages $\Delta M_{\text {total }}(N)$ is then the sum of all $\Delta m_{\text {total }}(n)$ increments $(n=1, \ldots N)$. The cleaning method impacts the ratio between $m_{a}$ and $m_{b}$, and then the wear rate. This will be discussed in section 3.1.

With this procedure, the frequency of cleaning (number of contacts between two successive cleaning schemes) can be changed, keeping all other parameters constant. Also, the amounts of wear debris deposited on the disk surface or stuck to the sample surface can be estimated separately.

Figure 7 shows the force profile during one wear-loop. One highlight of the device we developed is the fast closed loop control of the normal force. The set point for the normal force is a square pulse. This allows us to maintain a constant normal force during the whole tests, even with changes of temperature, wear of the sample, etc.. The applied normal force is obtained through fast closed loop control, which insures that the normal force is regulated much faster than the onset of the full sliding of the sample, as illustrated in Figure 7.

The wear-loop initiates when the actuator compresses the sample against the disk surface, in about $25 \mathrm{~ms}$. Concomitantly, the sample is sheared, resulting in increase of the tangential force until it reaches the maximum value $F_{t}=\mu F_{z}$, where $\mu$ is the apparent friction coefficient and $F_{z}$ is the applied normal force. Meanwhile, the plateau at maximum value $F_{t}$ corresponds to the fully-sliding state. The critical time to reach such state depends on the normal force, friction coefficient and mostly on the sliding speed. Generally speaking, the critical time increases with a higher tangential force and a lower speed. In our tests, a constant sliding speed $V_{s}=5 \mathrm{~cm} / \mathrm{s}$ was chosen and an 


\section{Accepted Manuscript}

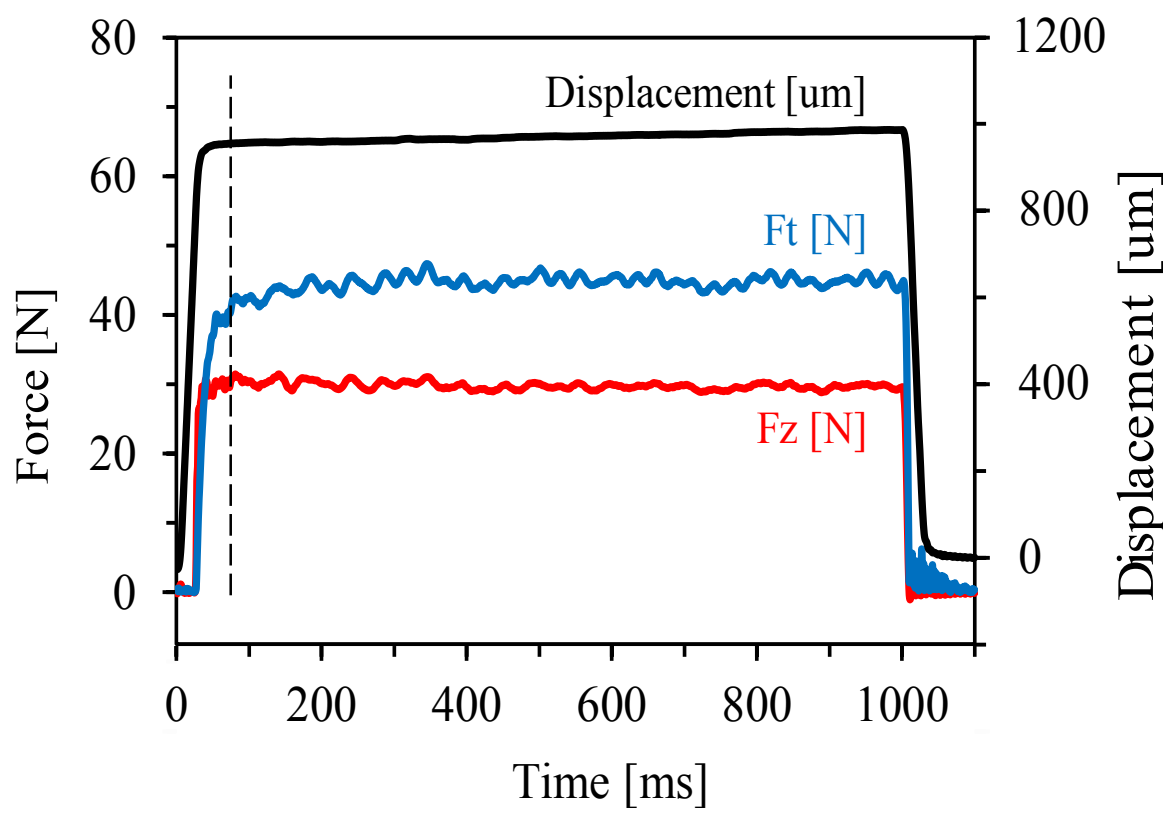

Figure 7: Profiles of the displacement, normal $\left(F_{z}\right)$ and tangential $\left(F_{t}\right)$ forces during one wear-loop. Contact duration is $1 \mathrm{~s}$. Vertical dashed line at about $80 \mathrm{~ms}$ indicates the onset of sample sliding. $\mathrm{C} 1$ sample. 


\section{Accepted Manuscript}

average value $0.068 \mathrm{~s}$ was always used. Thus, during the $i$ th wear-loop, the frictional energy $E_{1}$ was calculated as:

$$
E_{1}(i)=V_{s} \int_{t_{1}}^{t_{2}} F_{t}(t) d t
$$

where index $i$ refers to the wear-loop number, $t_{1}=0.068 \mathrm{~s}$ and $t_{2}=1$ $\mathrm{s}$ corresponds to the end of the contact duration. The total accumulated frictional energy $E_{a}$ after $n$th wear loop is obtained by:

$$
E_{a}(n)=\sum_{j=1}^{n} E_{1}(j)
$$

Wear results are reported in terms of weight loss as a function of total accumulated friction energy: $\Delta M_{\text {total }}(n)=f\left(E_{a}(n)\right)$. Note that both quantities (total weight loss and friction energy) scale with the overall contact area. As the real contact area is not measured quantitatively and the contact pressure is not uniform within the contact surface, we shall not express the results in terms of normal pressure. Instead, for each set of presented results, the normal force and sample diameter will be specified. The correspondence to average normal pressure value may be established as follows.

\section{Results and discussion}

Tribological tests have been performed on the materials described in section 2.1. Both samples are representative of (though not identical to) real materials used in tire treads. We shall first describe results of wear tests in terms of sample weight loss measured as a function of total friction energy.

\subsection{Linear wear and effect of track cleaning}

One key issue in wear tests of rubber materials is how to deal with the debris. It was found that the measured wear rate is strongly affected by the cleaning scheme used during the test.

The results of a series of tests performed with sample $\mathrm{C} 1$ are shown in Figure 8. All tests were done at room temperature with a normal force $30 \pm 1 \mathrm{~N}$ (see Fig. 7) and sample diameter $18 \mathrm{~mm}$. The contact time was $1 \mathrm{~s}$, the time interval between two successive contacts was $0.1 \mathrm{~s}$ and the sliding velocity $V_{s}=5 \mathrm{~cm} / \mathrm{s}$. All tests have a first step with the same conditions, 


\section{Accepted Manuscript}

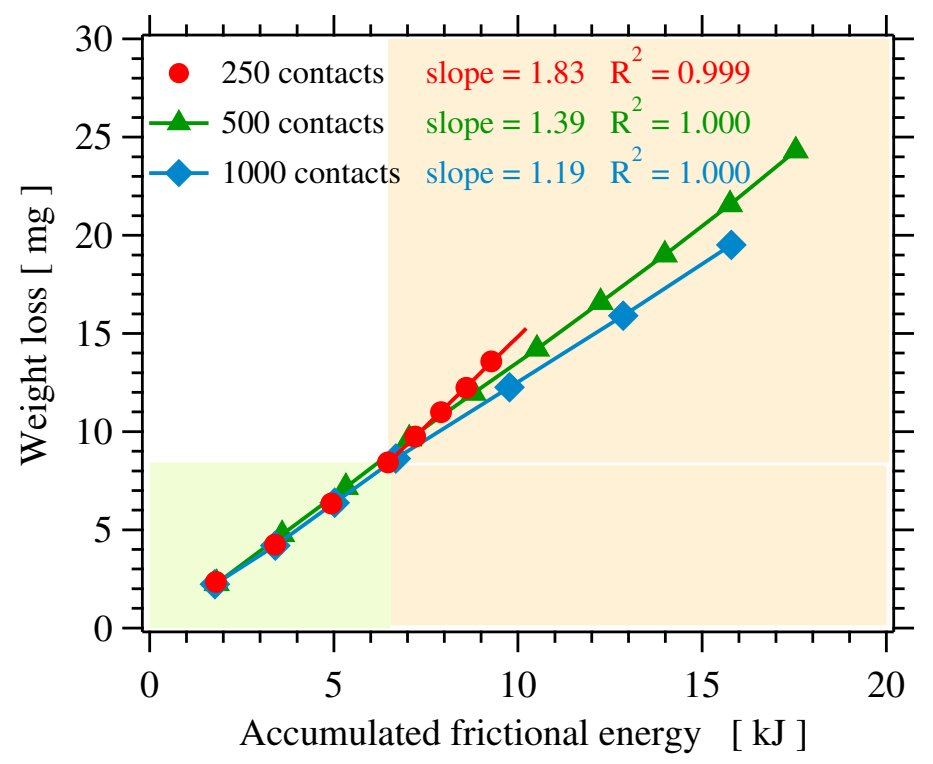

Figure 8: The effect of changing the cleaning frequency on wear rate in sample C1 (filled with carbon black N121) tested at room temperature under a fixed normal force of $30 \mathrm{~N}$, sample diameter $18 \mathrm{~mm}$. After 4 identical wear cycles of 500 wear loops (cleaning both disk and sample surface every 500 contacts), the cleaning rate was maintained (green) or changed to 250 (red) or 1000 (blue) loops. Best linear fits for each case are shown.

using an interval of 500 contacts between two successive cleaning operations (ranging from 0 to roughly $6.5 \mathrm{~kJ}$ friction energy), as indicated in Fig. 8. Results obtained during this first step illustrate the perfect repeatability of the measurements. A perfect linear relationship between the total friction energy and total weight loss is observed. Accordingly, a wear rate can be defined as the slope of the line $k_{a}=d \Delta m_{\text {total }} / d E_{a}(n)$ (in units $\mathrm{mg} / \mathrm{kJ}$ ).

After this first step, the cleaning frequency was either maintained to 500 contacts (green curve in Fig. 8) or changed to 250 (red curve) or 1000 ( blue curve) contacts. From the onset of this change, the relationship between weight loss and friction energy is still perfectly linear, but the slope (wear rate $k_{a}$ ) changes depending on the cleaning interval. The higher the cleaning frequency, the higher the wear rate. The dependance of the wear rate (the slope of the lines in the second stage of the tests in Fig. 8) on the cleaning frequency is illustrated in Figure 9. Fig. 9 also reports the average value of the wear debris left on the track during each wear stage $\overline{\Delta m_{\text {track }}(n)}$ for each 


\section{Accepted Manuscript}

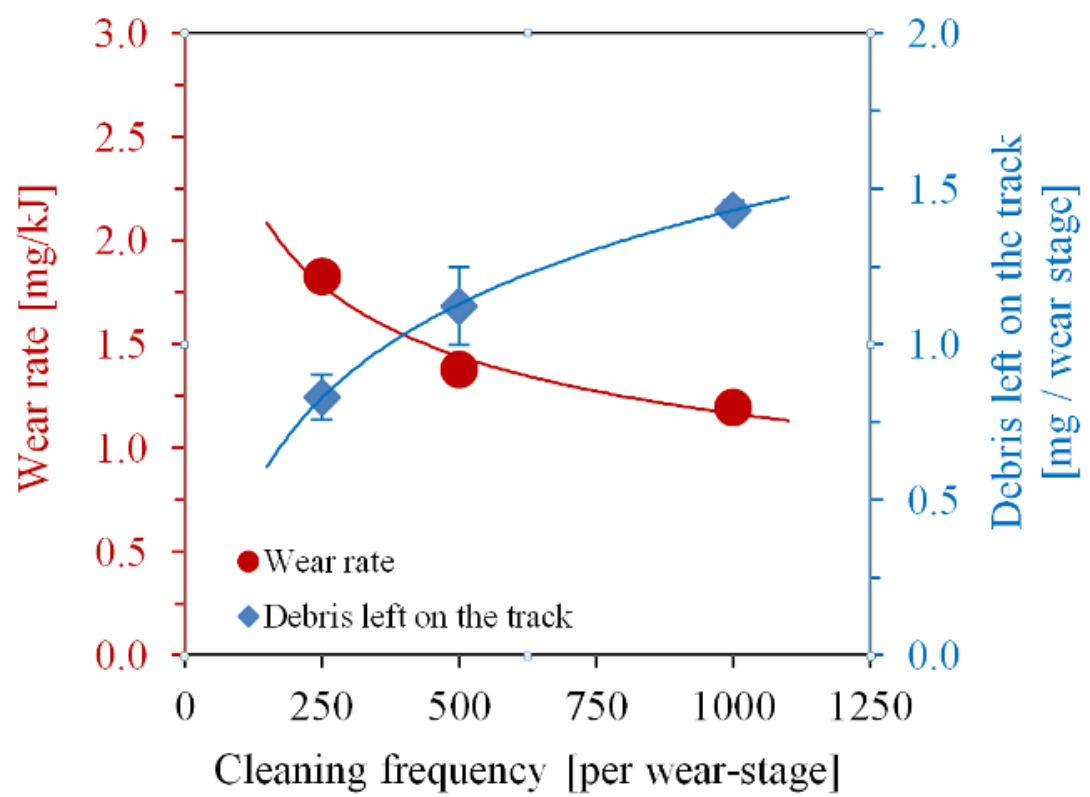

Figure 9: Wear rate (scale on left) and cumulated amount of wear debris left on the disk surface (scale on right) as a function of the number of contacts between two cleaning operations. Sample C1.

chosen value of the cleaning interval. Thus, it appears that a cleaner surface (that is, a surface that is cleaned more often) gives a higher wear rate $k_{a}$.

Note that for the carbon-black filled sample C1, a perfectly linear relationship is found up to $20 \mathrm{~kJ}$ total accumulated frictional energy when the cleaning frequency is maintained at 500 contacts.

Further results obtained with sample $\mathrm{C} 1$ are shown in Figure 10. In order to investigate a larger range of average normal pressure, the sample diameter was set to $10 \mathrm{~mm}$ with a normal force $20 \mathrm{~N}$, other conditions being the same as before. After the same wear-stage of 500 contacts for all tests, the number of wear-loops during each wear stage was changed to 35 wear-loops (green triangle), 96 wear-loops (blue circles) or maintained at 500 wear-loops (red diamonds). Again, results obtained during the first step illustrate the perfect reproducibility of the measurements. Note that the absolute values of the rate $k_{a}$ in Figures 8 and 10 are not fully comparable due to the difference in sample size and or normal pressure.

The tests shown in Figure 10 were repeated while changing the applied 


\section{Accepted Manuscript}

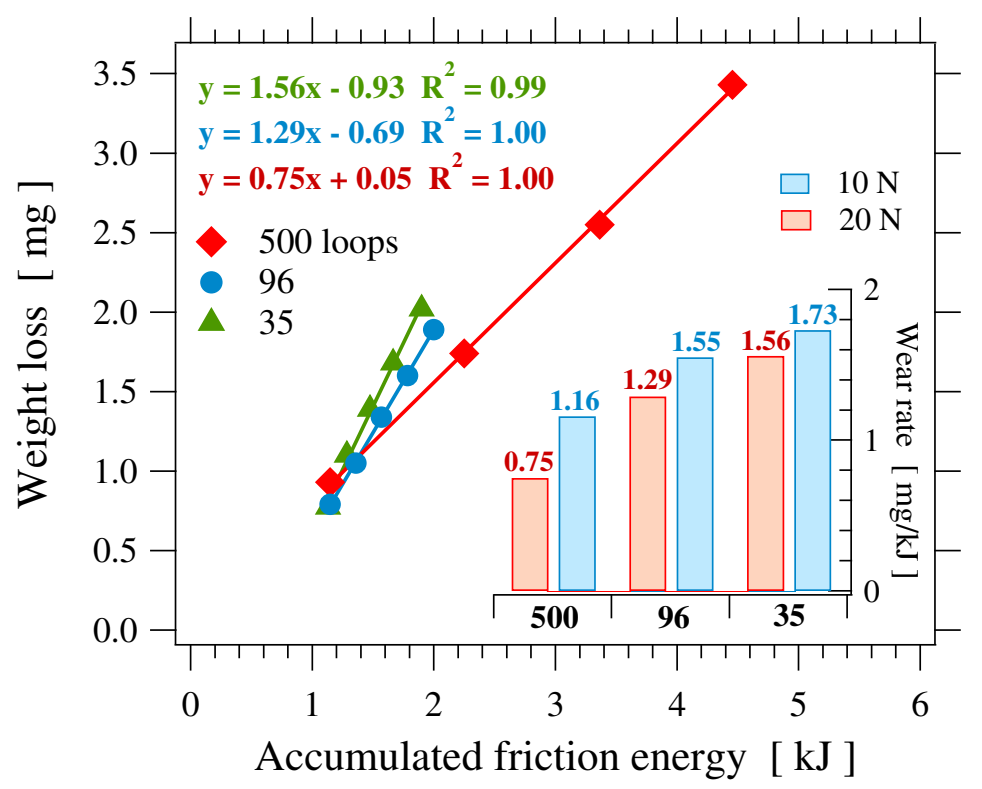

Figure 10: The effect of changing the cleaning frequency on the wear rate tested at room temperature under a fixed normal force of $20 \mathrm{~N}$. In the case of cleaning every 35 wearloops: the weight loss is only measured after each 3 wear-stages, as the weight loss in each stage of 35 wear-loops is too small. Lines are best linear fits. Inset: Wear rates measured at two different values of the normal force $(10 \mathrm{~N}$ and $20 \mathrm{~N})$ and three different cleaning frequencies (35, 96 and 500 wear-loops as indicated). Sample C1. 


\section{Accepted Manuscript}

normal force (or equivalently average normal pressure). The inset in Figure 10 shows a summary of the wear rate of $\mathrm{C} 1$ sample tested under different normal force values with various cleaning frequencies.

A discussed above, for a given value of the normal force, the wear rate decreases as the period of the cleaning operation increases. Then, for a given cleaning frequency, the wear rate $k_{a}$ decreases as the normal force increases. This result may appear counter-intuitive at first sight. Remember, however, that the wear rate, expressed here as the slope of the total weight loss vs friction energy, takes into account explicitly the increased friction energy due to higher normal, hence tangential, force. Note also that the relative difference in wear rates observed when the normal force is changed from 10 to $20 \mathrm{~N}$ becomes smaller when the cleaning frequency is higher, i.e. on a surface which is cleaner on average.

All these results may be rationalized by assuming that wear debris sticking on the sample or disk surface have a protective effect against rubber wear. Applying a higher pressure, i.e. more severe conditions, generates more frictional energy per wear-loop, which in turns generates a larger amount of debris. Due to this reason, although the total weight loss per wear-loop increases, the apparent wear rate $k_{a}$ decreases in tests at higher pressure, because the so-called protective effect is then higher. This difference becomes less pronounced as the overall average amount of debris is smaller, as illustrated in Fig. 10 (inset). For example, when cleaning every 35 wearloops (which corresponds to exactly 3 revolutions of the rotating disk), the difference between $10 \mathrm{~N}$ and $20 \mathrm{~N}$ tests is within $10 \%$.

Based on this idea, an "intrinsic" wear rate $k_{i}$ may be defined by extrapolation to an ideally clean surface, or equivalently to a cleaning frequency of one wear-loop. It should not depend on the pressure (at least within the current testing range)and should be higher than the rates measured here.

\subsection{Friction coefficient}

The impact of wear debris on the contact conditions, which affects the wear rate, is also demonstrated by the evolution of the apparent friction coefficient along a test. As reported earlier, the friction coefficient of rubber materials changes with applied normal force, due to the change in actual contact area. It also varies under different values of the sliding speed and temperature because of the viscoelastic nature of the material [40-43]. Here we show that it is also affected by cleaning. Figure 11 shows the apparent friction coefficient of the $\mathrm{C} 1$ sample tested under two different normal force 


\section{Accepted Manuscript}

values at room temperature. The apparent friction coefficient is defined as $\mu_{a}=\bar{F}_{t} / \bar{F}_{z}$, where $\bar{F}_{t}$ and $\bar{F}_{z}$ are the average tangential and normal forces, respectively, when full sliding occurs during a wear-loop (see Figure 7). Black arrows indicate the points at which the disk and the sample surfaces were fully cleaned, which also separate different wear-stages. In this case, each stage contains 96 wear-loops (about 8 revolutions of the disk), except for stage 1 which lasted 500 wear-loops for initiating the sample surface to a stable state. Each time after cleaning, $\mu_{a}$ shows a small, sudden increase, but then $\mu_{a}$ decreases very rapidly quite far below its original value during the first 12 wear-loops after cleaning (corresponding to the first revolution of the disk). It then increases back until it reaches a steady value. A tentative, qualitative explanation may be the following one. During the first revolution, the sample always makes contact with a clean disk. Only a fraction of the generated debris is transfered to the track and they accumulate wear-loop after wearloop. As noticed above, the presence of more debris tends to attenuate the severity of the contact, as is reflected by the lower wear rate under higher normal force (see inset in Figure 10). Thus, debris accumulation may lead to a decrease of $\mu_{a}$. After this first revolution, the sample starts to make contact with a disk surface covered by wear debris. However, debris are still being tranfered from the sample surface to the disk until some equilibrium state (transfer rate) is reached. As the adhesion force at rubber-rubber interface is presumably stronger than at the rubber-disk interface, the measured $F_{t}$, and thus $\mu_{a}$, values become larger. This process can last very long before reaching the equilibrium state. For example, as discussed above, although the wear rate $k_{a}$ measured for $F_{z}=10 \mathrm{~N}$ is larger than for $F_{z}=20 \mathrm{~N}$, the total amount of debris generated during each wear-loop for $F_{z}=20 \mathrm{~N}$ is larger (see Figure 10). This may possibly explain that the equilibrium state occurs faster for $F_{z}=20 \mathrm{~N}$ than for $F_{z}=10 \mathrm{~N}$.

\subsection{Non-linear wear observed in silica samples}

In the previous section, the linear wear behaviour of carbon black filled samples under different testing conditions has been shown. This also applies to the silica filled sample S2. There are some differences in the behavior of both samples, however. First, the rate $k_{a}$ of the $\mathrm{S} 2$ sample is significantly larger than in the $\mathrm{C} 1$ sample. For instance, the rate $k_{a}$ of $\mathrm{S} 2$ is 1.60 and 1.12 when tested under a normal force of $10 \mathrm{~N}$ and $20 \mathrm{~N}$, respectively, at room temperature and for a wear-stage of 500 wear-loops, which is about $40 \%$ to $50 \%$ larger than in $\mathrm{C} 1$ sample. More interestingly, the silica-filled sample S2 


\section{Accepted Manuscript}

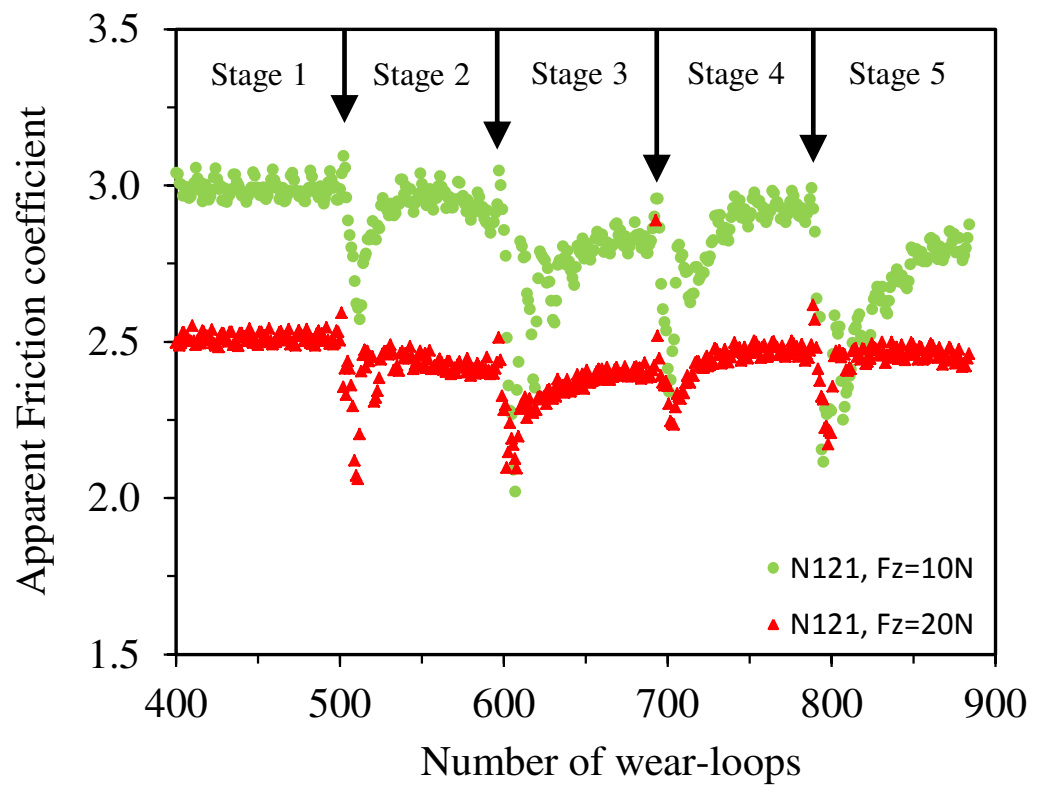

Figure 11: The evolution of the friction coefficient of sample C1 (filled with N121 carbon black) tested at room temperature under a normal force of $10 \mathrm{~N}$ (green) and $20 \mathrm{~N}$ (red). The disk and the sample surface was cleaned every 96 wear-loops. 


\section{Accepted Manuscript}

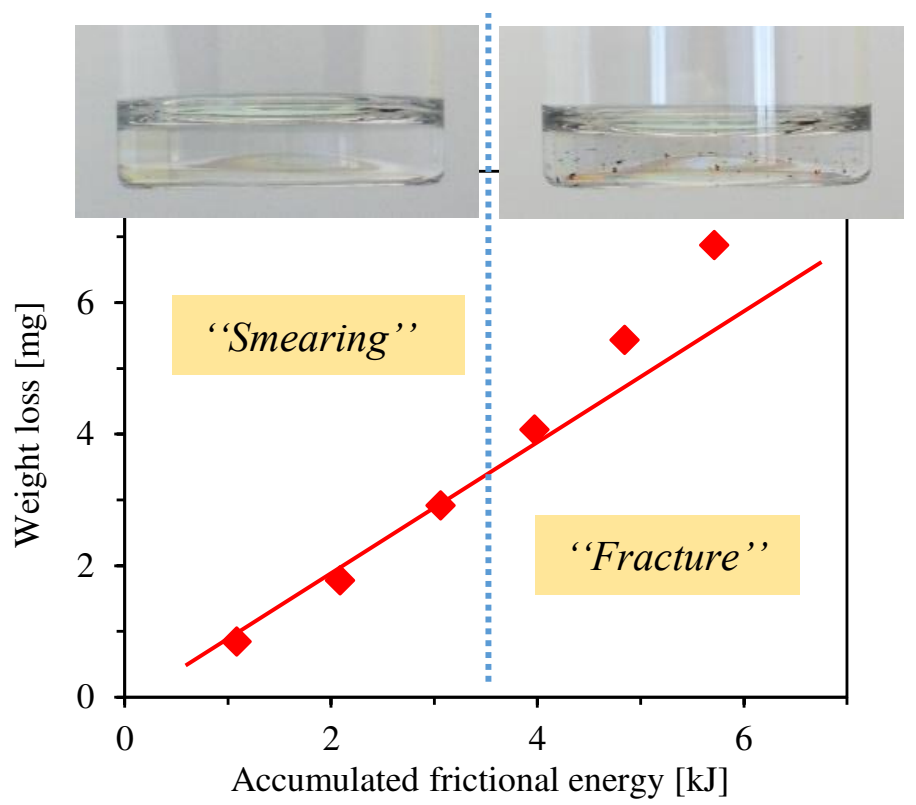

Figure 12: The wear behaviour of sample S2 (filled with Z1165 silica). The top figures show the solubility of the debris in toluene, collected either in the initial linear regime (left) or in the non-linear regime (right).

shows an increased wear rate after a few wear-stages. As shown in Figure 12, beyond a critical energy level of about $3.5 \mathrm{~kJ}$, the wear rate starts to deviate upwards with respect to the initial linear regime.

More importantly, beyond this value, the debris start to contain a small part which is insoluble in toluene. The top left and right pictures show the debris collected below and above approximately $3.5 \mathrm{~kJ}$ respectively, after 30 min sonication in toluene. Small unsoluble rubber particles can only be observed for the debris collected above approximately $3.5 \mathrm{~kJ}$.

This suggests that two distinct mechanisms are at play in successive stages of wear, or contribute to a different extent in successive stages. These mechanisms are discussed in the next sections.

\subsection{Sticky debris}

A shown above, two distinct types of wear debris could be collected along wear tests. The first one constitutes a layer sticked on the sample surface. A representative example is shown in Figure 13, which shows the presence 


\section{Accepted Manuscript}
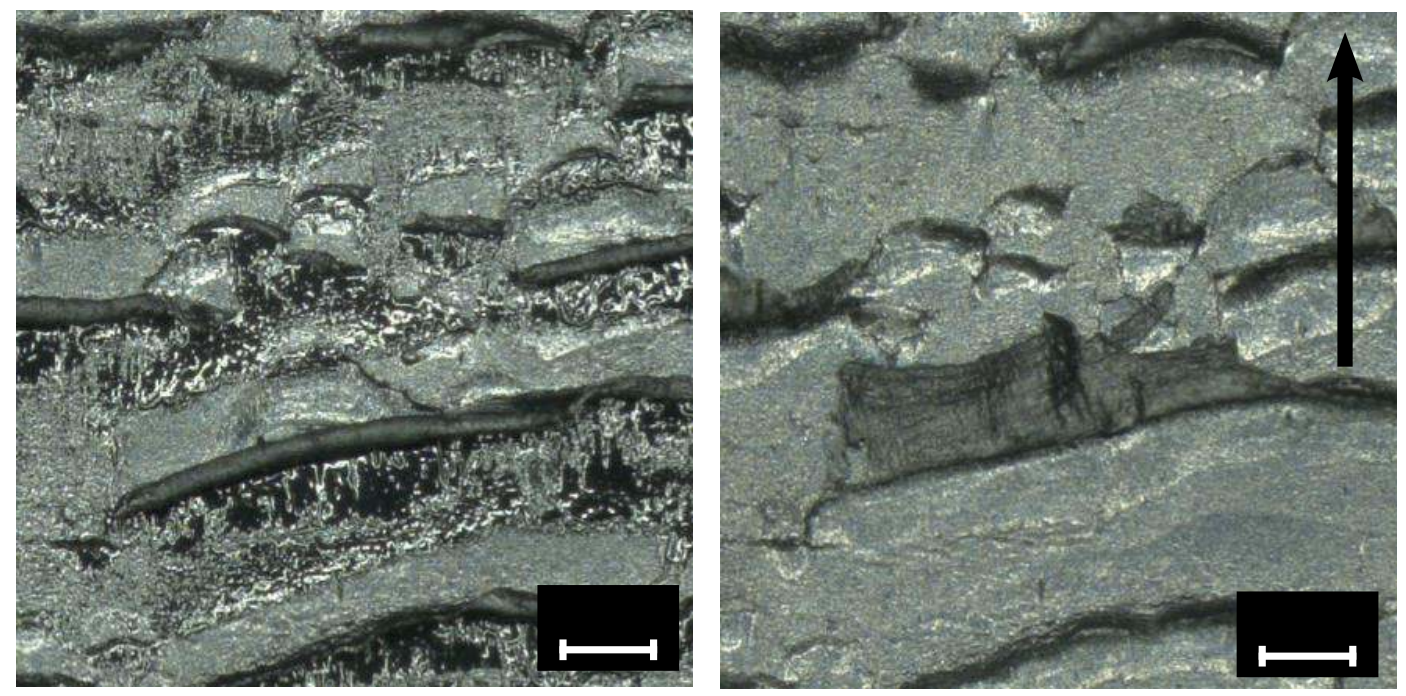

Figure 13: A representative snapshot of wear pattern in the S2 sample (from zone 5 in Figure 15 (b')), shown before (a) and after (b) cleaning the sample surface, showing the presence of a sticky layer of worn rubber accumulated on the sample surface before cleaning (a). This layer is removed by washing the surface (b). The black arrow indicates the sliding direction.

of a sticky layer of worn rubber on the sample surface before cleaning (a). This sticky layer accumulates in regions located behind wear ridges, which are protected by the presence of the protruding ridges and therefore are not in direct contact with the sliding abrading surface. This layer is removed at each wear stage by washing the surface, as illustrated in Figure 13(b).

The second type of wear debris is made of relatively large (from a few $\mu \mathrm{m}$ up to a few tens of $\mu \mathrm{m}$ or even larger) material fragments torn away from the sample. They may be mixed with sticky debris as shown in Figure 13. The corresponding wear mechanism becomes predominant when the ridge pattern has developed, after a transitory period at the beginning of the tests, during which ridge patterns are not yet developed. The duration of this period (in terms of the corresponding number of contacts) depends on the particular sample under study and on test control parameters.

A major difference was assessed by controlling the solubility of both types of wear debris in toluene (Top left picture in Figure 12). Sticky debris collected in the first stage of wear (case (a) in Figure 13) are soluble in toluene. This indicates that the associated mechanism corresponds to some degree of 


\section{Accepted Manuscript}

chemical degradation of the material, namely de-crosslinking and/or chain scission. After ageing for several days or more at ambient conditions, those debris become apparently unsoluble, but they can still be dissolved after sonication for about one minute. This may indicate that some bound rubber with relatively weak polymer-filler interactions was formed during ageing.

Conversely, wear debris collected in the later wear stages, for example the 4th stage, are not all soluble in toluene (Top right picture in Figure 12). This indicates that some of the collected debris correspond to bulk fragments of the material with a preserved local elastomer structure. For instance, the "tongue" part shown in Figure 13 may finally turn into such kind of insoluble debris.

The transition from the first ("chemical", or so-called "smearing") mechanism to the second one ("mechanical tearing") may correspond to a change in wear rate (as measured by the slope of the weight loss vs friction energy curves), as illustrated in Figure 12, which shows that the two successive stages of wear indeed correspond to different wear rates. In the first regime (which last up to about 3.5-4 kJ total accumulated friction energy for the particular sample studied here), debris consist of sticky layer. Chemical degradation is the predominent mechanism in this transitory regime. In the second regime (from about $3.5-4 \mathrm{~kJ}$ ), debris are mostly micrometric fragments. Mechanical tearing from the ridge pattern is the dominant mechanism. The crossover point between the two regimes under given test conditions depends on the particular sample under study.

For the C1 sample, sticky debris were mainly observed and larger debris particles did only appear in marginal amount, in the applied pressure range. This may due to the higher wear resistance provided by carbon black fillers.

Thermogravimetric Analysis (TGA) characterization of the unworn samples and wear debris was performed (Figure 14). TGA tests for sticky debris show a signficant weight loss (of order 18\%) in the temperature range between $200^{\circ} \mathrm{C}$ and about $340^{\circ} \mathrm{C}$, while larger size debris have a signal identical to that of the unworn material. This confirms that some chemical degradation has occurred specifically in sticky debris.

\subsection{Wear Patterns}

The competition between smearing and fracture wear mechanisms can be further confirmed by the observation of wear patterns. Generally speaking, a larger frictional force, obtained either by increasing $F_{z}$ or $\mu$, helps initiating fracture on the rubber surface and subsequently generating ridge patterns. 


\section{Accepted Manuscript}

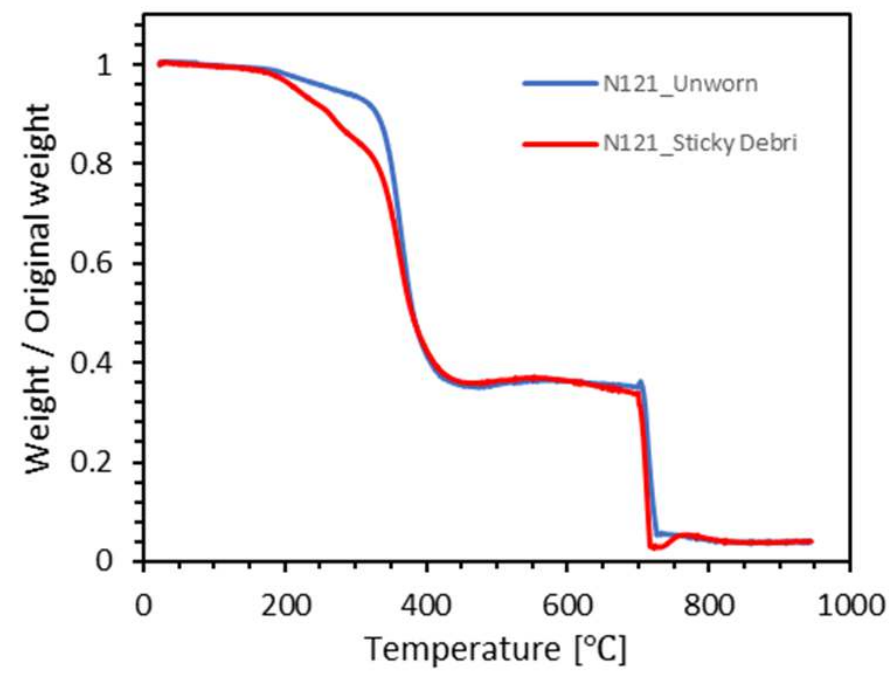

Figure 14: TGA spectrum of sticky debris and of the unworn C1 sample.

On the other hand, such increased frictional force also corresponds to a more severe test, which means that more energy will be released. This enhances the smearing effect, which works like 'melting' the patterns into sticky rubber. They together determine when and which kind of wear pattern can be formed. Figure 15 shows the surface of C1 and S2 samples after 2000 wear-loops (separated by 4 wear-stages in total in both cases) under different conditions. In (a), the surface looks smooth because the normal force was too small to fracture the sample surface (or, equivalently, because in this regime the smearing rate is larger than the 'crack growth rate'). When the normal force increases to $20 \mathrm{~N}$ (b), ridge patterns are clearly observed. However, at $60^{\circ} \mathrm{C}$, the increased smearing rate brings the surface to a smoother state again (Figure 15(c)). As silica filled samples show a lower wear resistance, ridge patterns are observed even for $F_{z}=10 \mathrm{~N}$ (a') and become more pronounced as $F_{z}$ increases to $20 \mathrm{~N}$ (b'). These more severe patterns are associated to the nonlinear wear behaviour and insoluble debris, as was shown in Figure 12. However, almost all large ridge patterns disappear at $60^{\circ} \mathrm{C}\left(\mathrm{c}^{\prime}\right)$. Although different testing conditions give different patterns and rates $k_{a}$, all cases shown in Figure 15 give very good linear fitting $\left(R^{2} \approx 0.999\right.$ or better $)$ except for the cases shown in (a') and (b'). Only under the corresponding test conditions does the fracture mechanism contribute significantly to the 


\section{Accepted Manuscript}

measured weight loss.

Figure 16 shows how the patterns change along the wear tests of the $\mathrm{C} 1$ sample under different conditions. The pictures come from similar locations on the sample surface, indicated as (a-c) fields in Figure 15. Under moderate condition (10 N, RT, 1-1 to 1-4), the ridge pattern gradually disappears because of smearing. As the normal force is increased, those small ridges merge and grow to larger patterns (2-1 to 2-4). As temperature increases, those larger patterns are gradually destroyed and evolve into non-connected 'dots' arranged in lines parallel to the sliding direction (3-1 to 3-4).

Due to the cylindrical sample geometry, there is a decreasing local pressure gradient from the center to the edge of the sample. A change of the wear pattern is observed accordingly. Figures 16 (a) to (c) respectively show the top, middle and bottom parts of the field d in Figure 15(b) (after 2000 wear-loops). Figure 17(a) has the lowest pressure as it is close to the worn area edge. Tiny ridges perpendicular to the sliding direction are observed. The distance between these ridges is of order $10 \mu \mathrm{m}$. They stand for the the initiation of the wear. In Figure 17 (b) (middle area, medium local pressure), solitary patterns are formed resulting from the growing of the initial ridges. They are larger in size but not fully connected. In Figure 17 (c) (higher local pressure), those patterns further grow up and connect to form an even larger size pattern. Such a connected pattern will keep growing in size and will finally be torn off from the sample surface. This is quite similar to the mechanism observed in blade abrasion test [23]. This process may be associated to the fracture wear mechanism.

\section{Conclusion}

We have developed a new rotary tribometer which allows performing accelerated laboratory wear tests. Contact parameters which are representative of real low severity wear conditions can be applied. The high quality of wear test results in terms of sensitivity and repeatability has been assessed.

The specific point emphasized in this paper is the strong impact of the presence of wear debris accumulated in the contact zone during the test. This impact was assessed by studying the dependence of the measured wear rate on the frequency at which wear debris are washed away from the contact. As a general conclusion, it may be said that the presence of debris has a protective effect of the sample surface against abrasive wear. This effect has been quantified. This emphasizes the importance of controlling the conditions in 


\section{Accepted Manuscript}

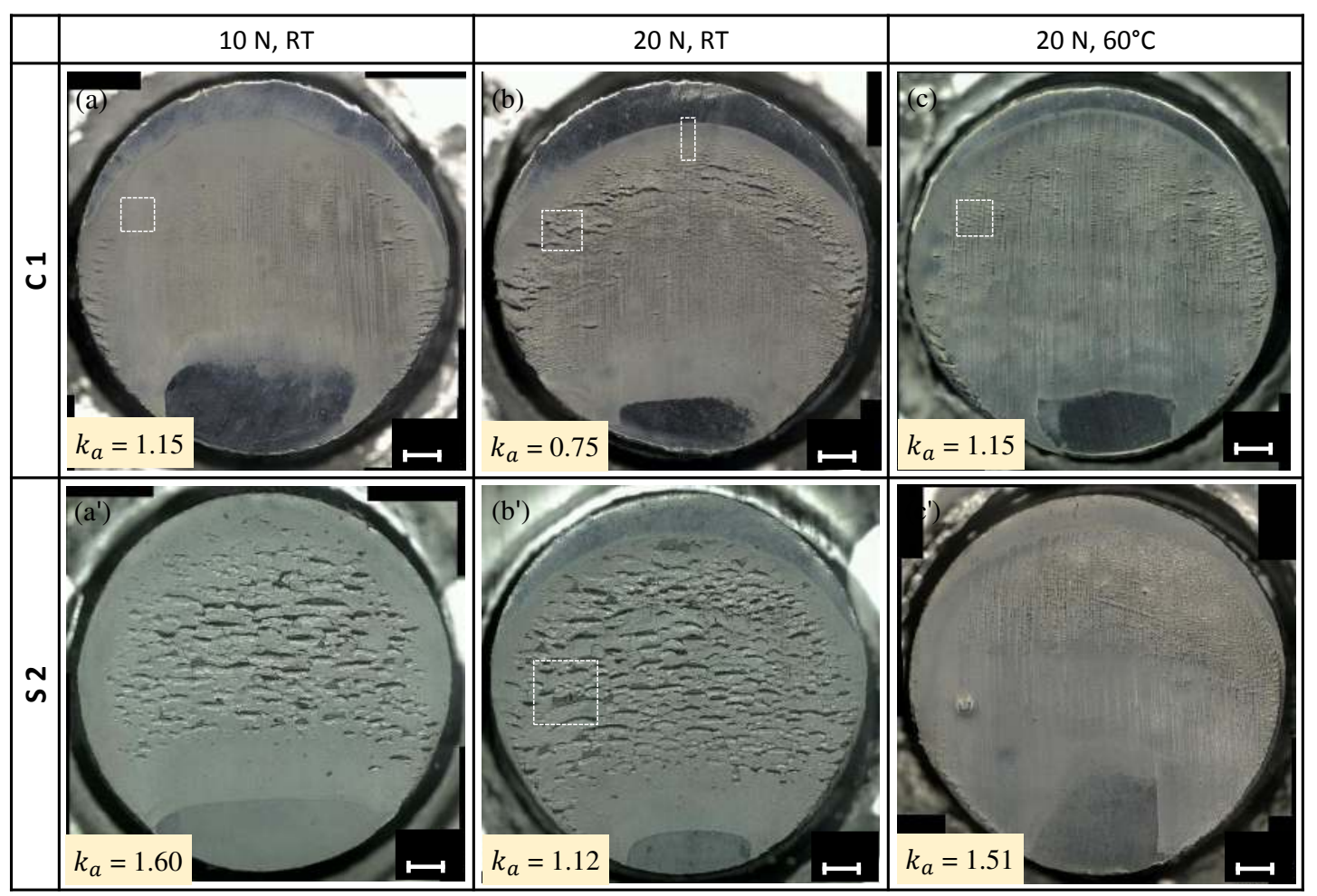

Figure 15: The cleaned surface of C1 (N121) and S2c (Z1165) samples after 4 wear stages of 500 wear-loops each, tested in the following conditions (a) (a'): $10 \mathrm{~N}$, room temperature; (b) (b'): $20 \mathrm{~N}$, room temperature; (c) (c'): $20 \mathrm{~N}, 60^{\circ} \mathrm{C}$. The evolution of the marked fields $1,2 \& 3$ along the test is shown in Figure 16 as: 1-1 to 1-4 (field 1), 2-1 to 2-4 (field 2) and 3-1 to 3-4 (field 3) respectively. Area 4 is directly zoomed in and shown in Figure 17. Area 5 is zoomed in in Figure 13. Normal (unprimed) labels refer to the C1 sample, primed labels to the S2 sample. For each test, the measured wear rate is indicated in the bottom left corner of the corresponding pattern. The sliding direction is vertical upwards. 


\section{Accepted Manuscript}

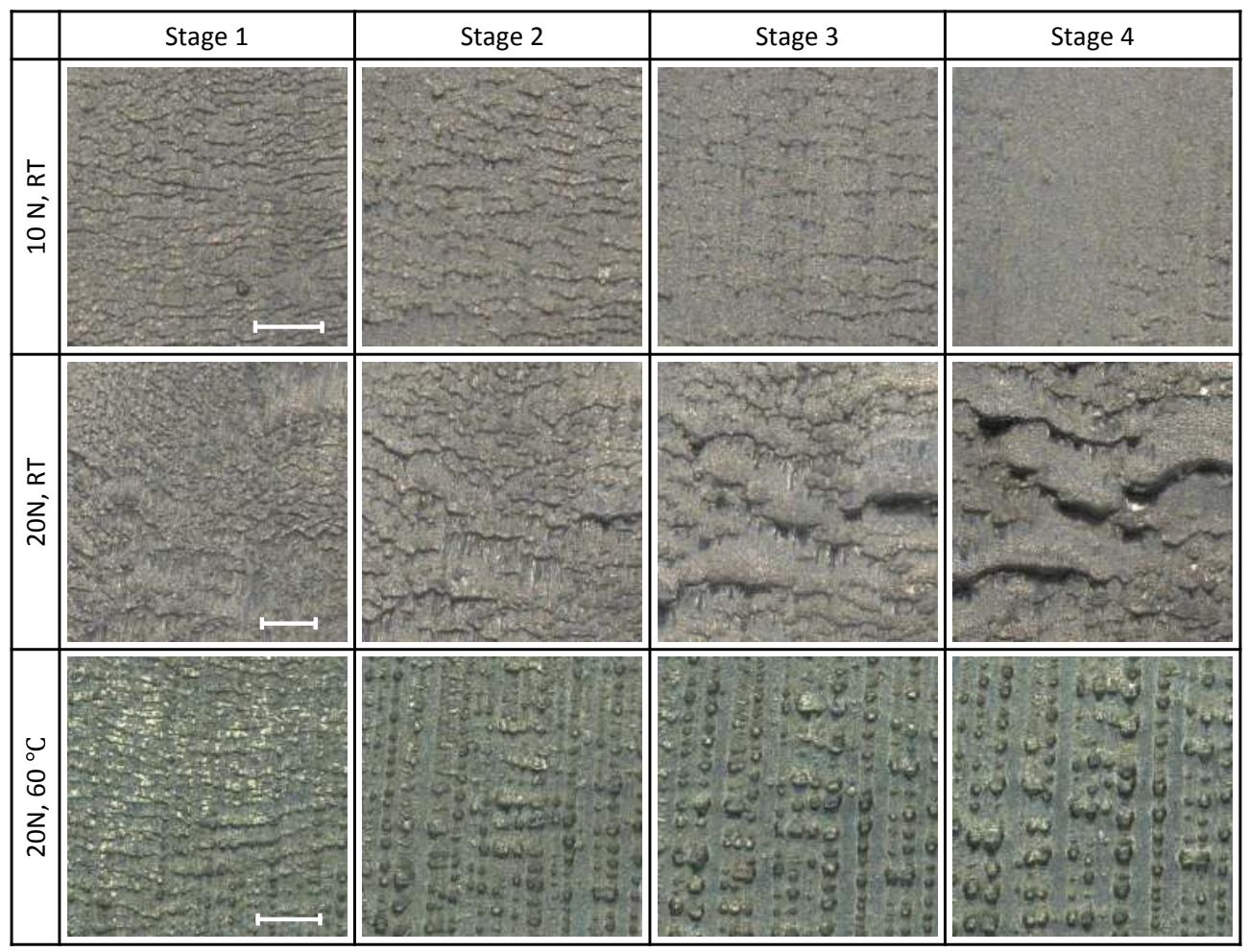

Figure 16: The evolution of the wear pattern of $\mathrm{C} 1$ sample tested under $10 \mathrm{~N}$, room temperature (1-1 to 1-4, area 1 in Figure 15); 20N, room temperature ( 2-1 to 2-4, area 2) and $20 \mathrm{~N}, 60^{\circ}$ (3-1 to $3-4$, area 3 ). Second indices $1,2,3$ and 4 refers to the end of wear-stages $1,2,3$ and 4, namely, after 500, 1000, 1500, 2000 wear-loops, respectively. The scale bar in 1-1 (resp. 2-1, 3-1) applies to 1-2 - 1-4 (resp. 2-2 - 2-4, 3-2 - 3-4). The sliding direction is vertical upwards. 


\section{Accepted Manuscript}
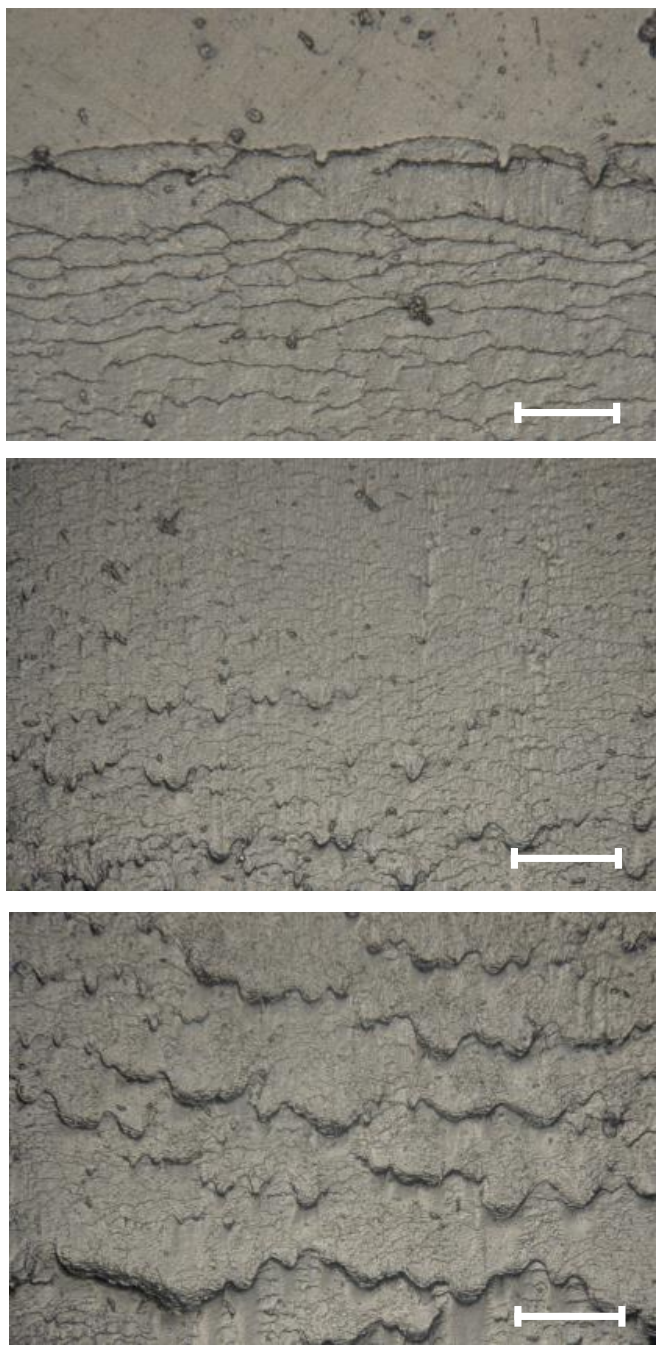

Figure 17: Images of $\mathrm{C} 1$ sample after 2000 wear-loops under a normal force of $20 \mathrm{~N}$ at room temperature. (a), (b) and (c) are zoomed-in from the top, middle and bottom of area 4 in Figure 15(b) respectively. The sliding direction is vertical upwards. 


\section{Accepted Manuscript}

which wear debris are eliminated from the contact. To mimic real usage conditions and provide truly representative 'open cycle' conditions, wear debris should be washed away from the contact as often as possible. However, one may wonder whether wear rate in service may depend on the amount of tire debris accumulated on a road surface. This amount may probably vary to large extent depending on atmospheric conditions, traffic, the type of road and so on.

Carefully analyzing wear wastes also has allowed discriminating two distinct types of wear debris. At the beginning of the tests, wear debris essentially consist in a sticky layer of soluble (thus de-crosslinked elastomer material). As tests are continued further on, a new regime occurs with a well established ridge pattern, in which the predominant wear mechanism is due to tearing away of material fragments of micrometric sizes. These fragments are made of unsoluble -thus with a locally preserved crosslinked structureelastomer material.

The proposed testing procedure allows generating selectively and discriminating quantitatively the various wear mechanisms. It emphasizes a predominant control parameter, which is the amount of wear debris present within the contact zone.

\section{Acknowledgements}

Part of this study was performed within the FP7 European Collaborative Project LORRY (Grant Agreement number: 314463), whose funding is acknowledged. This study was also partly funded by Solvay, which is gratefully acknowledged. We thank Yinping Tao from QMUL for her help in performing TGA tests.

\section{Conflicts of interest}

The authors declare no conflict of interest.

\section{References}

[1] A. G. Veith, A review of important factors affecting treadwear. Rubber Chemistry and Technology 65 (1991) 601-659.

[2] A. H. Muhr, A. D. Roberts, Rubber abrasion and wear, Wear 158 (1992) 213-228. 


\section{Accepted Manuscript}

[3] K. A. Grosch, Rubber friction and its relation to tire traction, Rubber Chemistry and Technology 80 (2007) 379-411.

[4] G. Petitet G. and M. Barquins M., Matériaux caoutchoutiques - Morphologie, formulation, adhérence, glissance et usure, ed. p.p.e.u. romandes. 2008.

[5] K. A. Grosch and A. Schallamach, Relation between abrasion and strength of rubber. Rubber Chemistry and Technology 39 (1966) 287305.

[6] Z. Mané, J.-L. Loubet, C. Guerret, L. Guy, O. Sanseau, L. Odoni, L. Vanel, D. R. Long, P. Sotta, A new rotary tribometer to study the wear of reinforced rubber materials, Wear 306 (2013) 149-160.

[7] A. Schallamach, Abrasion of rubber by a needle, Journal of Polymer Science 9 (1952) 385-404.

[8] A. Schallamach, Abrasion pattern on rubber, Transactions Institution of the rubber Industry 28 (1952) 256-268.

[9] A. Schallamach, On the abrasion of rubber, Proceedings Institution of the Physical Society - Section B 67B (1954) 883-891.

[10] M. M. Reznikovskii, G. I. Brodskii, Feature of the mechanism of abrasion of highly elastic materials, in Abrasion of Rubber, James D I Ed., McLaren Palmerton, 1967.

[11] K. A. Grosch, A. Schallamach, The load dependence of laboratory abrasion and tyre wear, Kautschuk und Gummi Kunststoffe 22 (1969) 288292.

[12] M. Heinz, K. A. Grosch, A laboratory method to comprehensively evaluate abrasion, traction and rolling resistance of tire tread compounds, Rubber Chemistry and Technology 80 (2007) 580-607.

[13] A. K. Bhowmick, Ridge formation during the abrasion of elastomers, Rubber Chemistry and Technology 55 (1982) 1055-1062.

[14] C. T. R. Pulford, Failure of rubber by abrasion, Rubber Chemistry and Technology 58 (1984) 653-661. 


\section{Accepted Manuscript}

[15] Y. Uchiyama, Wear of rubber through roll formation, International Polymer Science and Technology 12 (1985) 51-62.

[16] M. Barquins, Friction and wear of rubber-like materials, Wear 160 (1993) $1-11$.

[17] Y. Fukahori, H. Yamazaki, Mechanism of rubber abrasion. 1. Abrasion pattern-formation in natural-rubber vulcanizate, Wear 171 (1994) 195202.

[18] Y. Fukahori, H. Yamazaki, Mechanism of rubber abrasion. Part2. General rule in abrasion pattern formation in rubber-like materials, Wear 178 (1994) 109-116.

[19] Y. Fukahori, H. Yamazaki, Mechanism of rubber abrasion. Part3: how is friction linked to fracture in rubber abrasion?, Wear 188 (1995) 19-26.

[20] R. Ramakrishnan, J. A. Donovan, The effect of abrading surfaces on the wear of rubber tread compounds, Rubber Chemistry and Technology 68 (1995) 609-622.

[21] Y. S. Kim, H. S. Byun, S. Kim, A. N. Gent, Abrasion of selected rubber compounds with a DIN abrader, Korea Polymer Journal 7 (1999) 116123.

[22] T. Iwai, Y. Uchiyama, K. Shimosaka, K. Takase, Study on the formation of periodic ridges on the rubber surface by friction and wear monitoring, Wear 259 (2005) 669-675.

[23] H. Liang, Y. Fukahori, A. G. Thomas, J. J. C. Busfield, Rubber abrasion at steady state, Wear 266 (2009) 288-296.

[24] H. Liang, Y. Fukahori, A. G. Thomas, J. J. C. Busfield, The steady state abrasion of rubber: Why are the weakest rubber compounds so good in abrasion?, Wear 268 (2010) 756-762.

[25] G. Petitet G., Contribution à la compréhension des mécanismes élémentaires d'usure douce des élastomères chargés réticulés, $\mathrm{PhD}$ thesis, École Centrale de Lyon, 2003.

[26] E. Genin-Blanchard, Étude des mécanismes d'usure élémentaire des élastomères chargés réticulés, PhD thesis, École Centrale de Lyon, 2006. 


\section{Accepted Manuscript}

[27] Gent, A. N.; Pulford, C. T. R., Mechanisms of rubber abrasion. J. Appl. Polym. Sci. 1983, 28 (3), 943-960.

[28] Gent, A. N., Abrasion of rubber by a blade abrader: effect of blade sharpness and test temperature for selected compounds, Rubber Chemistry and Technology 69 (1996) 819-833.

[29] G. Heinrich , Hysteresis friction of sliding rubbers on rough and fractal surfaces, Rubber Chemistry and Technology 70 (1996) 1-14.

[30] B. N. J. Persson, E. Tosatti, Qualitative theory of rubber friction and wear, Journal of Chemical Physics 112 (2000) 2021-2029.

[31] A. G. Thomas, Factors influencing the strength of rubbers, Rubber Chemistry and Technology 48 (1975) 902-912.

[32] Southern, E.; Thomas, A. G., Studies of rubber abrasion. Rubber Chem. Technol. 1979, 52 (5), 1008-1018.

[33] B. J. Briscoe, S. K. Sinha, Wear of polymers, Proc Instn Mech Engrs: Part J: J Engineering Tribology, 216, 401-413 (2002).

[34] V.H. Nguyen, D. Zheng, F. Schmerwitz, P. Wriggers, An advanced abrasion model for tire wear, Wear 396-397, 75-85 (2018).

[35] S. W. Zhang, Wet abrasion of polymers, Wear 158, 1-13 (1992).

[36] V. A. Coveney; C. Menger, Behaviour of model abrasive particles between a sliding elastomer surface and a steel counterface, Wear 240, 72-79 (2000).

[37] G. Kraus, Mechanical losses in Carbon Black Filled Elastomers, Journal of Applied Polymer Science 39 (1984) 75-92.

[38] Y. Bomal, S. Touzet, R. Barruel, P. Cochet, B. Dejean, Developments in silica usage for decreased tyre rolling resistance, Kautschuk Gummi Kunststoffe 50 (1997) 434.

[39] D. Wang , X. Chen, X. Xie, H. Stanjek, M. Oeser, B. Steinauer, A study of the laboratory polishing behavior of granite as road surfacing aggregate, Construction and Building Materials 89 (2015) 25-35. 


\section{Accepted Manuscript}

[40] K. A. Grosch, Relation between friction and viscoelastic properties of rubber, Proceedings of the Royal Society of London A: Mathematical, Physical and Engineering Sciences, 274, 21-39 (1963).

[41] D. F. Moore, The friction and lubrication of elastomers, Oxford, G.B., 1972 .

[42] M. Barquins, A. D. Roberts, Rubber friction variation with rate and temperature: some new observations, J. Phys. D: Appl. Phys. 19, 547563 (1986).

[43] A. Le Gal, L. Guy, G. Orange, Y. Bomal, M. Klüppel, Modelling of sliding friction for carbon black and silica filled elastomers on road tracks, Wear 264, 606-615 (2008).

[44] J. F. Archard, Contact and rubbing of flat surfaces, Journal of Applied Physics 24 (1953) 981-988.

[45] A. Schallamach, The load dependence of rubber friction, Proc. Phys. Soc. B 65, 657-661 (1952). 